\title{
College Libraries and Resource Sharing: Testing a Compact Disc Union Catalog
}

\section{Charles T. Townley}

In 1990, the seventeen collegiate members of the Associated College Libraries of Central Pennsylvania tested a compact disc union catalog to determine its effect on resource sharing in a college library consortium. This article reports the outcomes of the test in the areas of bibliographic quality, user evaluation, public relations strategies, and operating guidelines. Desired enhancements and additional research needs are identified. Recommendations are made for the use of compact disc union catalogs in college library consortia.

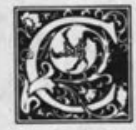

ollege libraries form networks and consortia to improve local services through coordinated action. Nowhere is this more true than in resource sharing. Alone, a college library cannot afford enhanced collections in more than a few subject areas. Yet, by banding together, college library collections can form a virtual research library to the benefit of faculty and students at all participating institutions.

The practical problem has been how to identify, request, and deliver desired material among participating libraries in an effective manner. This can be likened to building a three-legged stool for resource sharing where all three legs are necessary for effectiveness. Over the years college library consortia have developed several means for sharing resources, including union card catalogs and serials lists for identification, interlibrary loan for requests, and the use of mail, reciprocal borrowing, and delivery services for exchanging materials. ${ }^{1}$

Recent technological advances create both opportunities and challenges for re- source sharing among college libraries. Machine-readable bibliographic records and electronic public-access catalogs improve local access but are difficult and expensive to link together with a common command language. Enhancements in telecommunications make contact possible, but most college library consortia cannot afford dedicated telecommunications among members. And national networks, like Internet, currently do not reach many smaller colleges. Delivery services can be expensive, and telefacsimile quality can be inadequate, particularly for tables and illustrations.

CD-ROM technology offers convenient and inexpensive local copies of a machinereadable union catalog within a college library consortium. Updated on a periodic basis from member library records, a CD-ROM union catalog offers the potential to achieve bibliographic control necessary for effective college library resource sharing. $C D-R O M$ union catalogs at each participating institution can be used for identifying needed material, initiating requests, and encouraging

Charles T. Townley is Dean of the University Library at New Mexico State University, Las Cruces, New Mexico 88003-0006. 
use of preferred delivery techniques. This article reports on a CD-ROM union catalog, named C. D. Cat, developed by the seventeen members of the Associated College Libraries of Central Pennsylvania (ACLCP). ${ }^{2}$ Reported are outcomes of the project in the areas of bibliographic quality, user evaluation, public relations strategies, and guidelines for continuing operations. Additional research needs are identified and desired enhancements described. Recommendations are made for the use of compact disc union catalogs in other college library consortia.

\section{BACKGROUND}

The Associated College Libraries of Central Pennsylvania is a consortium of seventeen college libraries, the Dickinson Law School, and the State Library of Pennsylvania. Now celebrating its twentyfifth anniversary, ACLCP has long been a leader in college library cooperation, attracting more than $\$ 1,000,000$ in grants and projects during its existence. In 1968, it undertook the formation of Interlibrary Delivery Service, now a separately incorporated service transferring materials among more than 150 Pennsylvania libraries. ${ }^{3}$ In 1983, ACLCP organized telefacsimile communications among academic libraries throughout Pennsylvania. These two services compose two legs of the resource-sharing stool for academic libraries in central Pennsylvania. ${ }^{4}$

In 1988, two external events encouraged ACLCP to add bibliographic control as the third leg of an effective resource-sharing stool. First, through the success of Access Pennsylvania (a union catalog of school, public, and publicly supported academic libraries), CD-ROM technology demonstrated that it could create a union catalog at low cost. ${ }^{5}$ Second, funding became available through Title II-D of the Higher Education Act to help defray the cost of developing and testing a CD-ROM union catalog among the seventeen college libraries. ACLCP prepared and received funding for a $\$ 134,000$ proposal based on the Intelligent Catalog product developed by the Library Corporation. ACLCP personnel spent the first eighteen months of the project in planning and development activities described in a previous article. ${ }^{6}$

In January 1990, each ACLCP collegiate library received an Intelligent Catalog station and a test CD-ROM disc containing 1,086,778 bibliographic records from seven of the seventeen participating libraries (see table 1). ACLCP personnel used the catalog to test a new linked-and-merged database design that joined records with the same Library of Congress card and/or OCLC control number. The test reduced the number of entries by 35 percent to 709,523 master records. Authority control was not attempted, but Library of Congress crossreferences were included. The Intelligent Catalog software permitted searching, using traditional author, title, and subject approaches, Boolean (keyword) searching, and several artificial intelligence techniques, including mapping and readers' adviser services. Users

TABLE 1

TEST DATABASE STATISTICS

\begin{tabular}{lcc}
\hline Member Library & No. of Records Used & No. of Master Records \\
\hline Bucknell University & 316,880 & 206,848 \\
Dickinson College & 221,573 & 98,854 \\
Elizabethtown College (partial) & 7,879 & 2,954 \\
Franklin \& Marshall College & 213,587 & 213,541 \\
Harrisburg Area Community College & 64,600 & 29,484 \\
Juniata College & 70,607 & 30,414 \\
Kutztown University & 191,652 & 127,520 \\
Total & $1,086,778$ & 709,523 \\
\hline
\end{tabular}


could manipulate records they selected, leave notes for library staff, and print out their results.

\section{GOALS, OBJECTIVES, TESTING}

The ACLCP union catalog seeks to complete a bibliographic resource-sharing system among the member libraries of the Associated College Libraries by providing bibliographic control through a CD-ROM union catalog. Objectives include:

1. Assuring adequate bibliographic quality to permit identification of materials held in member libraries;

2. Providing user-friendly access to library users;

3. Developing user-education programs that result in desired user behavior;

4. Generating user support adequate to assure continued production of the catalog.

The test period extended from January to June 1990. Each participating library provided a minimum of six weeks of public access during the test period. Each ACLCP library helped evaluate C. D. Cat and its success in achieving union catalog objectives.

\section{BIBLIOGRAPHIC QUALITY}

The project advisory committee named an evaluation committee comprised of individual members of ACLCP with experience in technical services and automation to evaluate the bibliographic quality of bibliographic database. ${ }^{7}$ This committee solicited comments from all project participants. The committee evaluated this information and made recommendations to the vendor.

The evaluation committee found the database capable of identifying materials held in member libraries. The committee found the linked-and-merged design a very effective means of controlling multiple entries without the cost of a fully de-duped database. While duplicate records did occur because some records did not contain the linking Library of Congress card or OCLC control number, many records were merged using this process. Indeed, the number of entries in the database was reduced by 35 percent from $1,086,778$ records to 709,523 records by using the linked-and-merged design. The danger of false merges - when matching records do not contain correct $\mathrm{LCCN}$ or OCLC control numbers-proved to be an insignificant issue. Some 497,641 (70 percent) records showed only one location, suggesting the uniqueness of college library collections and the strength to be gained when cooperating college libraries develop a common source of bibliographic information.

\section{The role of public relations and bibliographic instruction should be to guide responsible use of the consortially created research library.}

Several troublesome bibliographic problems did occur in the test database. One member's location stamps were incorrectly read so that all holdings were placed in a branch library. A number of minor call number variations, which might make it difficult to identify shelf locations from C. D. Cat data alone, were identified. The committee identified several sorting problems with the title fields. The vendor did not follow the requested order for entering member library databases, which resulted in less complete bibliographic records serving as a master record from time to time.

The evaluation committee observed that the current database organization is inadequate in its handling of articles in foreign languages. The committee believed that if catalogers go to the trouble of providing indicators for articles in foreign languages, the vendor should be able to read and ignore them for filing purposes.

As an unexpected bonus, the creation of the catalog has enabled member libraries to identify and resolve a potentially disastrous problem with the hex code used for diacritical marks in foreign language material. The regional provider of data from a national bibliographic database had inadvertently set its hex code incorrectly when creating databases for member libraries. This resulted in 
spellings of prelude, for example, as prbelude. An analysis of records in C. D. Cat by personnel from Shippensburg University identified the source of this problem, which is now being corrected with the full cooperation of the regional provider.

The evaluation committee has approved the bibliographic quality of the C. D. Cat database for use in ACLCP. Committee members recommend the linked and merged design for operational use as an effective and inexpensive means of identifying bibliographic resources in a college library union catalog.

\section{USER EVALUATION}

A local coordinator named by each library director organized user evaluation at member libraries. Each local coordinator was trained on project objectives and guidelines, equipment, and use of the database at the beginning of the test period. Each local coordinator prepared a strategy for introducing the catalog intended to meet the needs of the local institution. Some coordinators emphasized direct use of C. D. Cat on a reference referral basis. Others developed bibliographic instruction programs, usually supporting courses with significant research assignments. Local coordinators kept a diary in which they indicated observed strengths and weaknesses of C. D. Cat as well as their suggestions regarding the catalog and its improvement.

Students, staff, and faculty who used the test database were asked to complete an evaluation questionnaire regarding its usefulness. These questionnaires were collected and analyzed by project personnel, and the results are incorporated in this article. Local coordinators discussed suggestions of particular merit at a summer workshop where they shared their experiences and plans.

Users reported using the catalog for the full range of subjects common to liberal arts colleges (see table 2). Historical topics were most popular, followed by arts and sciences. The catalog was useful for most subjects, including professional topics like business and health.
TABLE 2

MOST SEARCHED TOPICS OF C. D. CAT

\begin{tabular}{lcc}
\hline Topic & Frequency & $\%$ \\
\hline History & 42 & 19.4 \\
Arts & 28 & 12.9 \\
Sciences & 26 & 12.0 \\
Literature & 25 & 11.5 \\
Business & 20 & 9.2 \\
Religion & 20 & 9.2 \\
Political science & 16 & 7.5 \\
Health & 15 & 6.9 \\
Psychology & 14 & 6.5 \\
Sociology & 11 & 5.1 \\
Total & 217 & \\
\hline
\end{tabular}

The ease and speed of the catalog are its most popular features (see table 3 ). Screens are easily read and the keyboard is simple. Most users come with a known item or subject and are pleased to be able to find it quickly. The value-added features, including keyword searching and indexing, and artificial intelligence, like maps and first page of popular works, drew mildly positive responses from the small number of users who explored these features.

Many respondents indicated that there are no bad features in the union catalog. They cited as a negative feature that the test database only contained holdings from seven of the seventeen libraries. Staff users expressed dissatisfaction with slow speed when searching three or more keywords, which can take more than a minute.

Users reported overall success in using the compact disc catalog. Some 93 percent of users report finding useful information. Even when known item searches are carried out, users succeed 85 percent of the time. Several local coordinators and users prefer C. D. Cat features to their local public access catalog.

User behavior during the test period is considered predictive in estimating growth in delivery services that will be associated with the operational version of C. D. Cat (see table 4). During the test 


\section{TABLE 3}

EVALUATION OF C. D. CAT'S FEATURES

\begin{tabular}{|c|c|c|}
\hline Feature & Frequency & $\%$ \\
\hline \multicolumn{3}{|l|}{ Best features of C. D. Cat: } \\
\hline Easy, user-friendly & 153 & 37.8 \\
\hline Fast & 75 & 18.5 \\
\hline Access to other libraries (locations) & 54 & 13.3 \\
\hline Access to more material (quantity) & 45 & 11.1 \\
\hline Multiple search modes (keyword) & 25 & 6.2 \\
\hline Printer & 18 & 4.4 \\
\hline Technical features (first page, etc.) & 12 & 3.0 \\
\hline Prompts, help screens, phone & 9 & 2.2 \\
\hline Displays and keyboard & 8 & 2.0 \\
\hline Indexing of additional fields & 6 & 1.5 \\
\hline Total & 405 & \\
\hline \multicolumn{3}{|l|}{ Worst features of C. D. Cat: } \\
\hline None & 46 & 31.7 \\
\hline Slow & 14 & 10.0 \\
\hline Incomplete holdings & 13 & 9.7 \\
\hline Books not in this library & 10 & 7.0 \\
\hline No periodicals & 10 & 7.0 \\
\hline Training/hard to learn & 10 & 7.0 \\
\hline Cannot see what you are typing & 8 & 5.5 \\
\hline Multiple entries & 7 & 4.8 \\
\hline Prompts/help & 7 & 4.8 \\
\hline Incomplete printer citations & 7 & 4.8 \\
\hline Keyboard too sensitive & 6 & 4.1 \\
\hline No $\log$ off & 4 & 2.8 \\
\hline Unanticipated screen change & 3 & 2.1 \\
\hline Total & 145 & \\
\hline
\end{tabular}

period, direct reciprocal borrowing and personal use of other libraries were strongly encouraged, but use of this service by these patrons was disappointingly low (12 percent). Usage patterns do not appear to differ significantly, based on whether users learned about the database in bibliographical instruction or through a reference referral. Interlibrary loan remains the primary means of obtaining materials not available locally (28 percent). Allowing for the novelty of C. D. Cat during the test period, the data suggest that one hundred sessions on the
CD-ROM catalog will generate at least fifty interlibrary loan requests, or onehalf of a request per use (see table 5).

Several ACLCP libraries have decided to use C. D. Cat as a high quality backup for their local OPAC. During the test period, these libraries had occasions to test its adequacy when their local system was down. All reported it to be successful. Indeed, 31 percent of public users indicated they found material in the local library that was previously unknown. At least one library has ordered an additional C. D. Cat station for local OPAC backup purposes. 
TABLE 4

OVERALL USER SUCCESS

\begin{tabular}{lrrr}
\hline & Yes & \multicolumn{1}{c}{ No } & $\%$ \\
\hline $\begin{array}{l}\text { Found useful } \\
\quad \text { information }\end{array}$ & 282 & 20 & 93.4 \\
Found known item & 45 & 8 & 84.9 \\
\hline
\end{tabular}

\section{PUBLIC RELATIONS AND BIBLIOGRAPHIC INSTRUCTION}

Local coordinators and other interested ACLCP members, including representatives from the reference, bibliographic instruction, and circulation committees, met in June 1990 to review the recommendations of the technical committee, local coordinator diaries, and individual user data regarding the catalog. Local coordinators developed public relations strategies and bibliographic instruction models that would guide users in desired directions. Local coordinators concurred with the technical committee that bibliographic quality was excellent. They confirmed that the database had been well received among most participants.

Reference librarians recommend several changes to enhance public access. They believe that the reference librarian must introduce and interpret the union catalog. This introduction is especially important in college environments where connectivity with other colleges is usually limited to social and sporting events and does not include academic contacts like cross-listing of courses or shared computer resources. Further, it is considered important to guide users into desired behavior patterns, like recipro- cal borrowing or valuing quality of references, rather than quantity that can reduce delivery demand.

Local coordinators made several recommendations regarding changes to introductory screens so users can quickly determine that C. D. Cat is indeed a union catalog. Four ACLCP libraries also use the Intelligent Catalog technology for their local public access catalogs, and their users have particular problems distinguishing between the local and union catalogs. Another area of concern is that printouts provided by the machine should carry a banner indicating the availability of direct reciprocal borrowing to discourage interlibrary loan requests.

Addressing bibliographic instruction, local coordinators recommend that $C$. D. Cat be presented in faculty workshops at each college. They also suggest developing and using a common descriptive brochure in local workshops and bibliographic instruction. They feel C. D. Cat is most useful in advanced research courses and in support of faculty research.

Reference librarians, in general, do not like the artificial intelligence features of C. D. Cat. The mapping feature that provides access to geographically related topics is not detailed enough. The readers' adviser is for current best-sellers not academic works. Local coordinators believe the components developed as a part of Intelligent Catalog software are aimed at a school or pubic library audience and should be disabled or replaced with information appropriate for a collegiate audience.

\section{TABLE 5}

\section{USER BEHAVIOR}

\begin{tabular}{lrrrr}
\hline & \multicolumn{2}{c}{7 Test Libraries } & \multicolumn{2}{c}{ All Libraries } \\
\cline { 2 - 5 } Behavior & \multicolumn{1}{c}{ No. } & \multicolumn{1}{c}{$\%$} & No. & $\%$ \\
\hline Used local library & 48 & 30.9 & NA & NA \\
Used direct borrowing & 9 & 5.8 & 21 & 6.7 \\
Used other library & 9 & 5.8 & 21 & 6.7 \\
Requested ILL & 44 & 28.4 & 157 & 50.2 \\
Nothing & 19 & 12.3 & 67 & 21.4 \\
Other & 26 & 16.8 & 47 & 15.0 \\
Totals & 155 & & 313 & \\
\hline
\end{tabular}


Finally, local coordinators believe that the compact disc catalog sells itself. Once users are aware of the catalog, they are interested in using it. The role of public relations and bibliographic instruction should be to guide responsible use of the consortially created research library as a supplement for each library's local collection.

Interlibrary loan personnel are understandably concerned about the potential impact of C. D. Cat. With each two sessions on C. D. Cat predicted to generate one interlibrary loan request, interlibrary loan personnel believe the ACLCP library directors must provide additional support for interlibrary loan operations. They encourage reference librarians to counsel students to use the local library and reciprocal borrowing before requesting interlibrary loans. Interlibrary loan personnel also suggest that it might become necessary to limit the number of interlibrary loan requests from students, to encourage awareness of the differences between quality and quantity in terms of overly large bibliographies, or to follow the lead of one ACLCP library and charge fees for interlibrary loan copies.

Interlibrary loan personnel think it is essential that the OCLC control number and/or the LCCN number be provided as a part of the C. D. Cat printout to expedite the interlibrary loan process used by most ACLCP libraries. They also look forward to the creation of an interlibrary loan form on the C. D. Cat equipment that can be completed by users, down-loaded, and held for review and processing by interlibrary loan personnel. Both features will help in coping with increased demand.

Reciprocal borrowing needs additional encouragement and publicity. Signs on C. D. Cat stations and printout banners should encourage reciprocal borrowing. Bibliographic instruction should tout the advantages of using other libraries in person. One possible method of encouraging direct borrowing is to provide some form of reinforcement, possibly through gift or discount certificates, for those people who use it. While one concern is that a student without transportation is unable to use reciprocal borrowing in an effective way, it has been noted that most can find transportation for social and athletic events. Finally, librarians believe they have to encourage reciprocal borrowing by offering to call ahead to check on the availability of desired material until availability information is accessible on C. D. Cat, possibly through a dial-access modem to member library circulation systems.

\section{CONTINUING OPERATIONS}

Based on the positive assessments of bibliographic quality and user acceptance as well as on the development of promising public relations techniques that will guide use into desired areas, the General Policy Committee has endorsed the implementation of C. D. Cat on a continuing basis. Participating libraries will pay $\$ 550$ per year for equipment maintenance, staff coordination, and two CD-ROM databases each year. A C. D. Cat director will coordinate training, evaluation, and submission of local tapes. An advisory committee will continue to monitor the project and undertake substantive reviews every three years.

\section{DESIRED ENHANCEMENTS}

College libraries recommend several enhancements to make compact disc technology more effective in college library consortia. Interlibrary loan personnel believe college users are capable of creating and storing their own interlibrary loan requests directly on the C. D. Cat workstation. This will save valuable staff typing and verification time. In addition, ACLCP wants to add a telefacsimile or electronic mail card to the C. D. Cat station so that libraries can communicate interlibrary loan requests directly with other members without having to leave the union catalog workstation.

The consortium wants to add an already existing union list of periodicals to the catalog to reflect the complete serials collections of the participating libraries. At present, some local catalogs provide information on periodicals and others do not. Some show holdings and others do not. Using the union list as the only source of bibliographic information for serials will eliminate this inequity in records. 
Finally, ACLCP should take advantage of the presence of the union catalog to introduce articulated collection development among member libraries. While some duplication is desirable to support local instructional needs, C. D. Cat permits much better articulation for purchasing esoteric materials.

\section{NEEDED RESEARCH}

Additional research is required in creating components of artificial intelligence that are meaningful for academic library users. As a discipline, artificial intelligence has much to offer libraries in access bibliographic information. Students need guidance to appropriate information and an opportunity to become excited by the labyrinth of knowledge available in academic libraries. A readers' adviser function that could guide freshmen and sophomores to basic paper topics would be useful. Faculty need to be guided to the best research in their fields of study. Reference to related subject headings or related keywords would be helpful for faculty. Efforts to introduce artificial intelligence features into public catalogs should continue.

User behavior also needs to be better understood. Appropriate materials to support instruction need to be developed. Strategies that encourage direct reciprocal borrowing should be developed and evaluated for their effectiveness. Efforts stressing quality as well as quantity of information need to be developed. The effects of a union catalog on distance learning, student recruiting, and library use should be analyzed.

Costs and benefits of union catalogs versus linked systems and common command languages should continue to be analyzed. ACLCP members are inclined to see linked systems as the long-term solution to full resource sharing. But significant additional funding and research are needed. In the meantime, protocols for collection articulation can be developed, tested, and applied in a CD-ROM catalog environment. Perhaps availability information can be delivered from local catalogs on demand through modems. Periodical and serial subscriptions may constitute a good starting point for articulated collection development.

\section{RECOMMENDATIONS}

C. D. Cat represents the completion of a three-legged stool for resource sharing among the member libraries of ACLCP. Materials can be identified in C. D. Cat, solicited through interlibrary loan, and delivered through already existing delivery services, reciprocal borrowing, or telefacsimile. While much enhancement is possible and desired, ACLCP member libraries now provide virtual research library access to their collegiate communities and are well positioned to initiate articulated collection development among themselves.

\section{The successful test... indicates that CD-ROM technology can effectively address the resource-sharing needs of college library consortia.}

This successful test of C. D. Cat indicates that CD-ROM technology can effectively address the resource-sharing needs of college library consortia. The quality of the catalog as an accurate bibliographic resource is assured. It is both useful and popular for identifying needed materials. In addition, ACLCP has found it helpful in showing areas for improvement of local databases and OPACS. Public relations and administrative guidelines offer promise for encouraging use that is appropriate and desired.

College library consortia wanting to encourage resource sharing and lacking the funding for dedicated telecommunications, linked systems, and/or a common command language would do well to consider a compact disc union catalog. Such a catalog, located at each member library, demonstrates the efficacy of cooperation and the ability of college libraries to identify and deliver desired information. Appropriately designed for consortium needs and abilities, a catalog station, located at a member library, visually demonstrates how effective resource sharing can be. 


\section{REFERENCES AND NOTES}

1. Norman D. Stevens, "Library Networks and Resource Sharing in the United States: An Historical Overview," American Society for Information Science Journal 31:405-12 (Nov. 1980).

2. Member libraries include Albright College, Bucknell University, Dickinson College, Dickinson School of Law (not participating in this project), Elizabethtown College, Franklin and Marshall College, Gettysburg College, Harrisburg Area Community College, Juniata College, Kutztown University, Lebanon Valley College, Messiah College, Millersville University, The Pennsylvania State University at Harrisburg, Shippensburg University, State Library of Pennsylvania (not participating in this project), Susquehanna University, Wilson College, and York College of Pennsylvania.

3. Charles H. Ness, "Interlibrary Loan Developments: Pennsylvania," RQ 7114-116 (Spring 1968); Dwight Huseman, "Access to Materials in Pennsylvania: Interlibrary Delivery," Wilson Library Bulletin 59:262-63 (Dec. 1984).

4. Mark Wilson, "How to Set Up a Telefacsimile Network-The Pennsylvania Libraries Experience," Online 12:15-25 (May 1988); Charles Peguese, "Telefacsimile, The Pennsylvania Experience: A State Library's Perspective," in Research Access through New Technology ed. Mary Jackson (New York: AMS, 1989), p.88-89.

5. Doris M. Epler and Richard E. Cassel, "ACCESS PENNSYLVANIA: A CD-ROM Database Project," Library Hi-Tech 5:81-92 (Fall 1987).

6. Charles T. Townley, "The Value-added Compact Disc, Union Catalog of the Associated College Libraries of Central Pennsylvania: A Progress Report," College \& Research Libraries News 51:835-39 (Oct. 1990).

7. Members of the Evaluation Committee include Robert Gimmi (Shippensburg); Cathryn Hintze (Harrisburg Area Community College); Soo Lee (Messiah); Michael Lynch (Bucknell); Kristin Senecal (Dickinson); and James Fogarty (ACCESS Pennsylvania).

\section{IN FORTHCOMING ISSUES OF COLLEGE \& RESEARCH LIBRARIES}

An Authority Control Alternative for Small Colleges Joan M. Bechtel

Information Delivery Strategies and the Rural Student Sharon M. West

On the Merits of Direct Observation of Periodical Usage: An Empirical Study Marifran Bustion

Literature Reviews and Inaccurate Referencing: An Exploratory Study of Academic Librarians Peter Hernon and Cheryl Metoyer-Duran

Job Satisfaction Among Support Staff in Twelve Academic Libraries in Ohio Coleen Parmer and Dennis East

The Organizational Misfits

Patricia A. Suozzi and Sandra Kerbel

Research Notes

Conference Proceedings in Physics

H. H. Barschall and W. Haeberli 


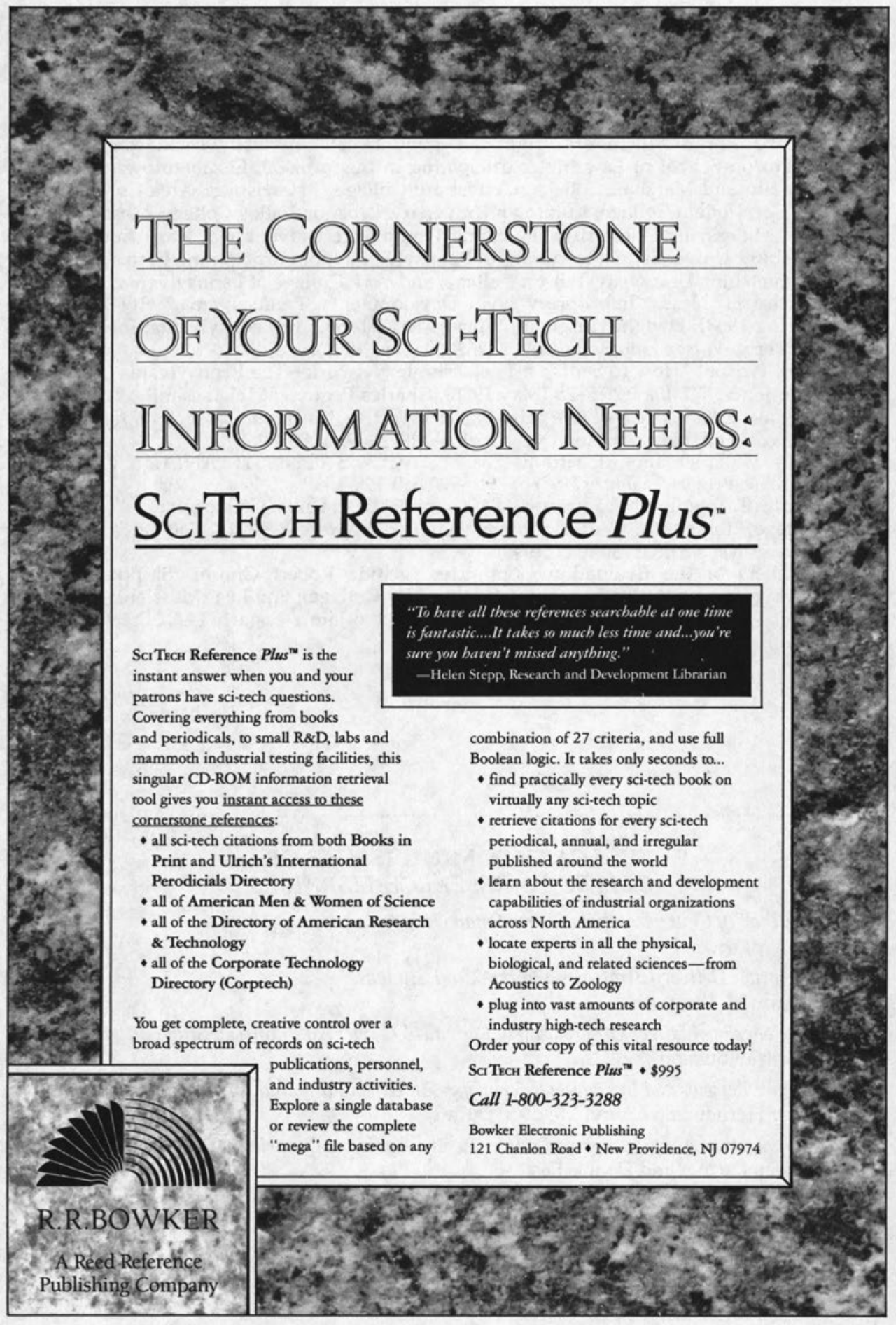

